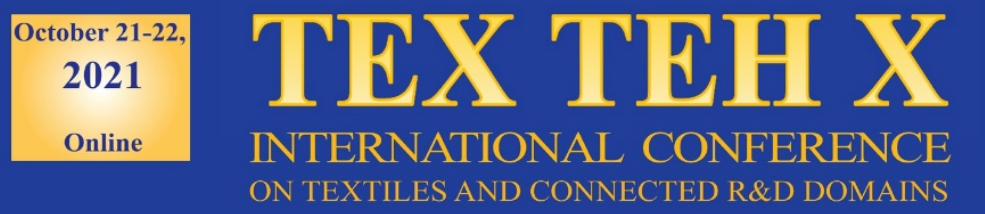

\title{
ELECTROSPINNING OF ST. JOHN'S WORT OIL LOADED MICROCAPSULES BASED PVA NANOFIBERS
}

DOI: $10.35530 /$ TT.2021.26

\author{
H.K. Güler ${ }^{1 *}$, F.C. Çallığlu' ${ }^{1}$, İ.Y. Mol ${ }^{1}$, M. Geysoğlu ${ }^{2}$ \\ ${ }^{1}$ Textile Engineering Department, Engineering Faculty, Süleyman Demirel University, Turkey \\ (E-mail: hulyakesici@sdu.edu.tr, fundacengiz@sdu.edu.tr, iremyagmurmol@gmail.com) \\ ${ }^{2}$ Bioengineering Department, Engineering Faculty, Süleyman Demirel University, Turkey \\ (E-mail: mustafageysoglu@sdu.edu.tr)
}

\begin{abstract}
In this study, it was achieved that the production of St. John's Wort oil loadad Eudragit RS 100/PVA microcapsules by emulsion/solvent evaporation method and the microcapsules were embedded in PVA nanofibers. Morphological analysis was carried out with SEM images of both microcapsules and nanofibers. The presence of St. John's Wort oil, PVA and Eudragit RS 100 polymers were confirmed in the chemical structure of microcapsules and nanofibers by FT-IR. According to experimental studies, microcapsules were produced to have a smooth surface, a spherical shape and a uniform particle size. The PVA concentration was kept constant at 10\% wt and microcapsule concentrations were applied as 1, 3, 5, 7, and 9 wt \%. Then, polymer solution properties were measured, such as conductivity, viscosity, and surface tension. It was determined that viscosity and surface tension values increased with microcapsule concentration increase, while conductivity did not change significantly. Nanofiber production was realized via the electrospinning method under the optimum process parameters. According to the SEM images and histogram, nanowebs have a fine fiber diameter, smooth surface, high quality and no bead structure. In addition, the average microcapsule size is $30 \mu \mathrm{m}$, average fiber diameter is $430 \mathrm{~nm}$ and the fiber diameter uniformity coefficient is 1,014. It is thought that this nanofiber surface containing microcapsules embedded in St. John's Wort has the potential to be used as a wound dressing.
\end{abstract}

Keywords: electrospinning, emulsion/solvent evaporation, microcapsule, nanofiber; St. John's Wort oil

\section{INTRODUCTION}

Eudragit RS 100 is a biocompatible, low-cost, high-strength, water-insoluble polymer that is commonly utilized as a wall material in extended-release microcapsules. Due to its low permeability, it is advantageous for drug release. In addition, Eudragit RS 100 is an easy-to-use and easy-to-process polymer in all forms, such as aqueous dispersions, granules, organic solutions, powders or ready-to-use powders [1]. As a core material to load into microcapsules within the scope of the study, St. John's Wort oil is a medicinal plant that has been used for centuries for burns, wounds, inflammation of the skin, nerve pain and stopping bleeding. Hypericum perforatum L. has antibacterial, antimicrobial, antiviral, and anti-inflammatory effects as a pharmacological effect [2-4]. The emulsion/solvent evaporation method is the most common method used for microencapsulation of water-insoluble agents. Furthermore, the fact that oil-loaded microcapsules do not leak or crack after production contributes to the advantages of this technology. As that solvent can be evaporated rapidly by itself, by heat, or by mixing 
during production, there is no need for an addition to the system, making production easier and faster [5-6].

In literature, nanofiber incorporation of St. John's Wort oil studies are very limited. Girgin and Cengiz Çallığlu produced Poly(vinyl pyrrolidone) based nanofibers with different concentrations of St. John's Wort oil by emulsion electrospinning. They incorporated St. John's Wort oil into the nanofibers successfully and indicated that the biocompatible nanofibrous surfaces can be used as a wound dressing [7]. In this study, it was aimed at producing St. John's Wort oil loaded microcapsules via the emulsion/solvent evaporation method and then, production of PVA nanofibers containing microcapsules by the electrospinning method. In addition, considering the limited number of studies about nanofibers containing microcapsules in the literature, it can be said that this study will make a great contribution to the literature.

\section{MATERIALS AND METHODS}

\subsection{Materials}

For microcapsule production, Eudragit RS 100 (Evonik Röhm GmbH) and Polyvinyl alcohol (Mn=88,000, 88\% hydrolyzed) were used as shell materials. St. John's Wort oil (Botalife, Isparta, Turkey) was used as a core material. Polyvinyl alcohol ( $\mathrm{Mn}=88,000,88 \%$ hydrolyzed) was used as the main polymer, distilled water and chloroform (Sigma-Aldrich Corporation (St. Louis, MO, USA)) were used as the solvent for nanofiber production.

\subsection{Methods}

Initially, microcapsules were produced by a solvent/evaporation technique. While producing microcapsules first, the oil phase and water phase were prepared to generate emulsion. The Eudragit RS 100 polymer was dissolved in chloroform to form an oil phase. The core ingredient, St. John's Wort oil, was then added. Meanwhile, the water phase was prepared by stirring PVA and the surfactant with pure water in a high-speed mixer. Then, the oil phase was added dropwise to the water phase and mixed in a high-speed mixer for 1.5 hours at $350 \mathrm{rpm}$. Finally, washing with $100 \mathrm{~mL}$ distilled water, filtering, and drying processes at room temperature were carried out. Then, a polymer solution containing $10 \mathrm{wt}$ \% PVA and 1, 3, 5, 7 and 9 wt \% microcapsules were prepared to produce nanofibers (Table 1). The polymer solutions were characterized by conductivity (Selecta CD 2005), viscosity (Lamy Rheology, B-One Touch Screen) under shear rate of $5 \mathrm{~s}^{-1}$ and surface tension (Biolin Scintific Sigma 702) by the Du Noüy ring measurements. Nanofibers were produced with the electrospinning method under process parameters such as $21.7 \mathrm{kV}$ voltage, $1.5 \mathrm{~mL} / \mathrm{h}$ feed rate, $18.1 \mathrm{~cm}$ distance between electrodes, $30 \pm 2 \%$ humidity, and $25.5 \pm 1^{\circ} \mathrm{C}$ temperature. The composition of PVA polymer solutions with various microcapsule concentrations is given in table 1 .

Table 1. Composition of PVA polymer solutions with microcapsules

\begin{tabular}{|c|c|c|}
\hline Sample Codes & PVA Concentration (\%) & Microcapsule Concentration (\%) \\
\hline PVA-0 & 10 & 0 \\
\hline PVA-1 & 10 & 1 \\
\hline PVA-3 & 10 & 3 \\
\hline PVA-5 & 10 & 5 \\
\hline PVA-7 & 10 & 7 \\
\hline PVA-9 & 10 & 9 \\
\hline
\end{tabular}

After experimental studies, both microcapsules and nanowebs were investigated morphologically by SEM images with different magnifications. ImageJ software was used 
to measure the diameters of 100 fibers obtained from various parts of the electrospun web. The number average and weight average values were estimated using the following equations.

$$
\begin{aligned}
A_{n} & =\frac{\sum n_{i} d_{i}}{\sum n_{i}} \text { (number average) } \\
A_{w} & =\frac{\sum n_{i} d_{i}^{2}}{\sum n_{i} d_{i}} \text { (weight average) }
\end{aligned}
$$

where $d_{i}$ is fiber diameter, $n_{i}$ - fiber number.

The ratio of $A_{w} / A_{n}$ was used to obtain the fiber uniformity coefficient, the same as it did for molar mass distributions. An optimum value is close to 1 , which indicates fibers that are uniform in size [8]. The histogram curve for fiber diameter was provided in the form of SPSS.

In addition, FT-IR analysis was performed to determine the presence of microcapsules in the nanofiber structures.

\section{RESULTS AND DISCUSSION}

For this study, firstly microcapsule production was carried out via the emulson/solvent evaporaton method. SEM images of St. John's Wort oil loaded Eudragit RS 100/PVA microcapsules are shown in figure 1.
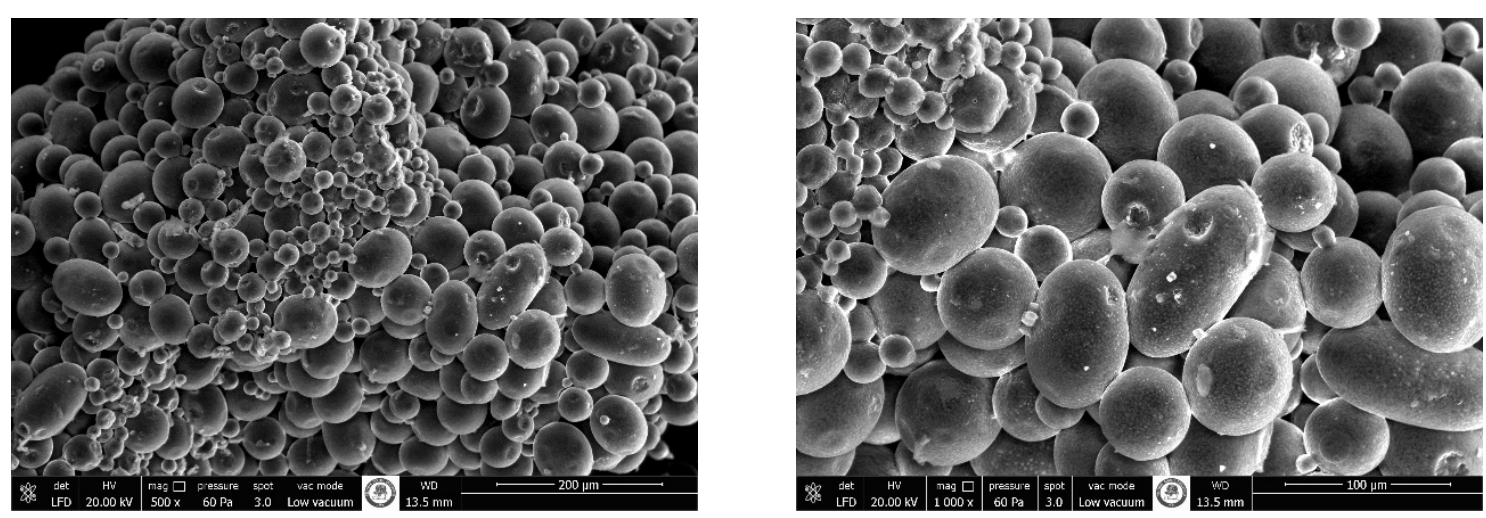

Figure 1. SEM images of microcapsules (500x and 1.000x)

As seen from the SEM images, St. John's Wort oil loaded Eudragit RS 100/PVA microcapsules have a spherical shape, a smooth surface and uniform particle size distribution. Average microcapsule size is $30 \mu \mathrm{m}$. Solution properties (conductivity, viscosity and surface tension) of PVA solutions include different concentrations of microcapsules' were measured. The results of solution properties are given in fgure 2 .

According to figure 2, it has been seen clearly that viscosity and surface tension increased with microcapsule concentration increase. However, conductivity did not change significantly. The morphology of PVA-0 nanofibers was investigated via SEM images and histogram (figure 3).

From the SEM images of figure 3, it has been observed that good nano web quality, fine, uniform and bead-free nanofibers were obtained. As it has been seen from the histogram, the average fiber diameter is $430 \mathrm{~nm}$ and the fiber diameter uniformity coefficient is 1.01. Moreover, there is a unimodal histogram curve and the nanofibers are quite uniform. 


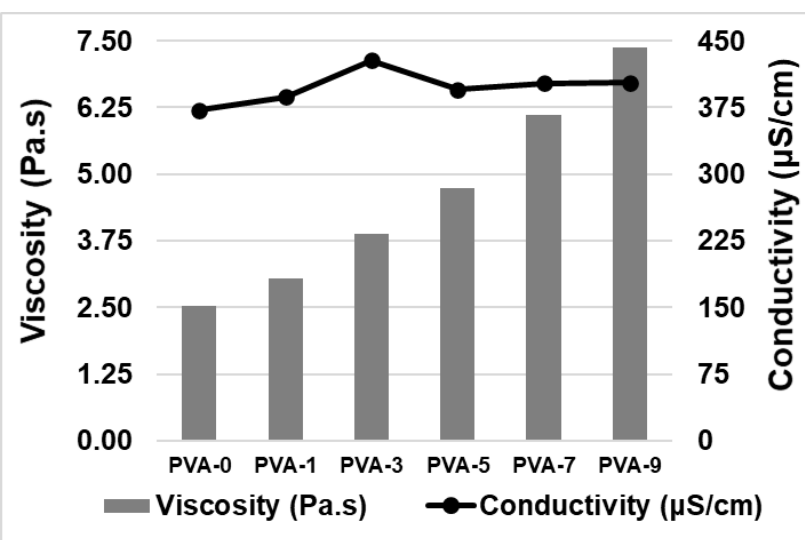

(a)

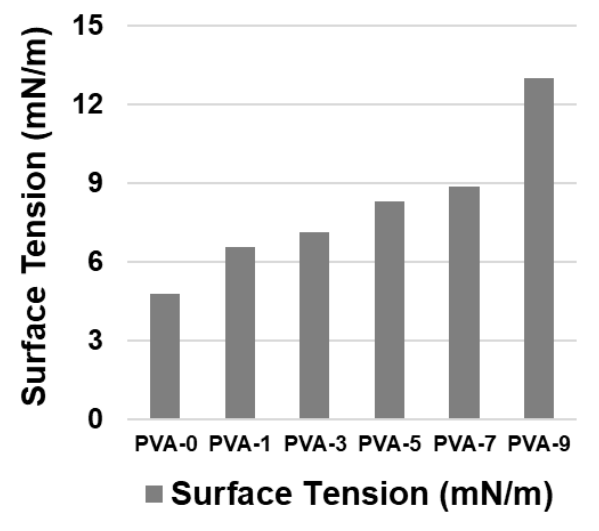

(b)

Figure 2. Solutions properties of PVA polymer solutions with different concentration of microcapsules a) Viscosity and conductivity b) Surface tension
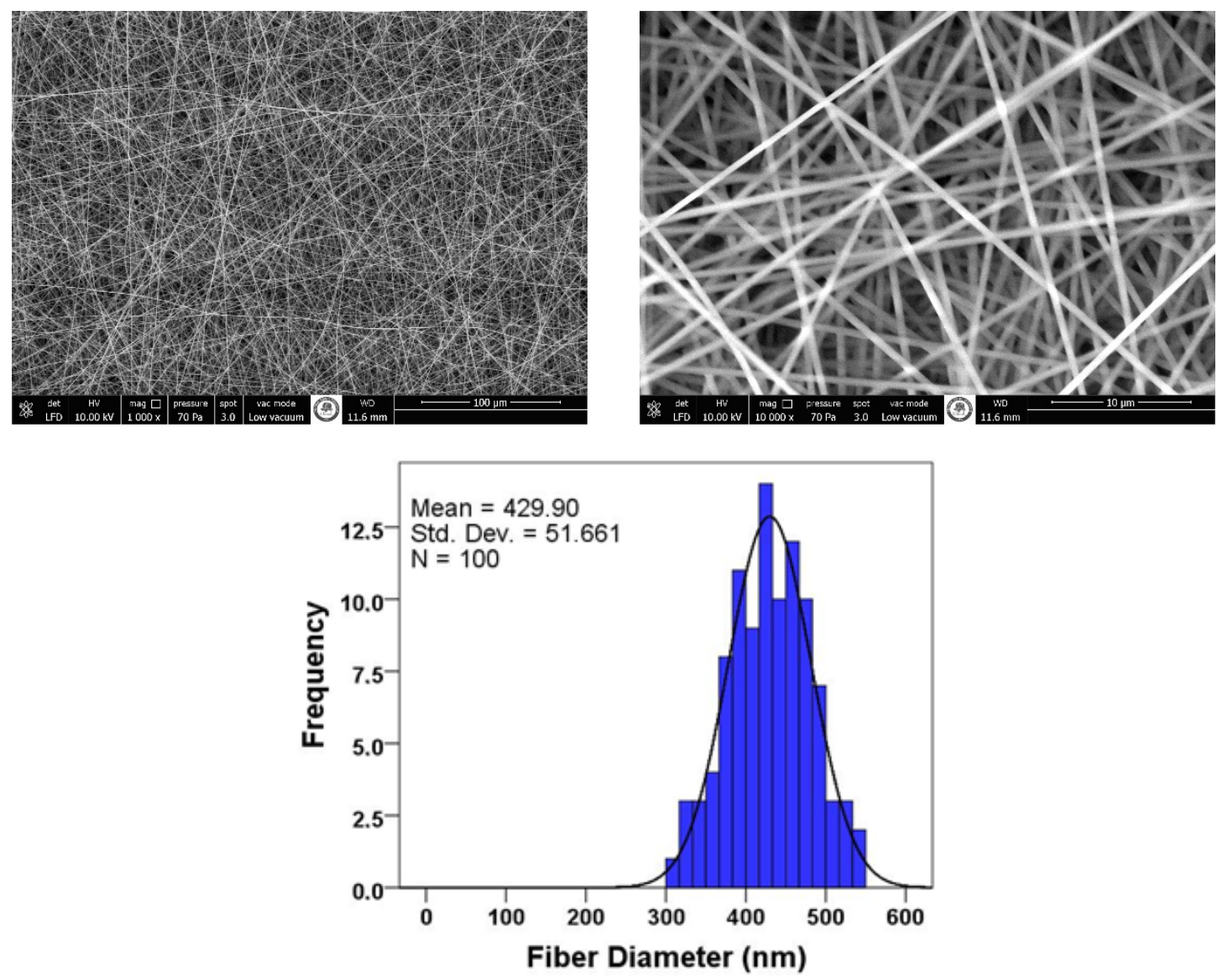

Figure 3. SEM images (1.000x and 10.000x) and histogram of PVA-0 nanofibers

The morphology of PVA nanofibers with various concentrations of microcapsules such as $1,3,5,7$, and 9 wt \% was investigated via SEM images (figure 4). 

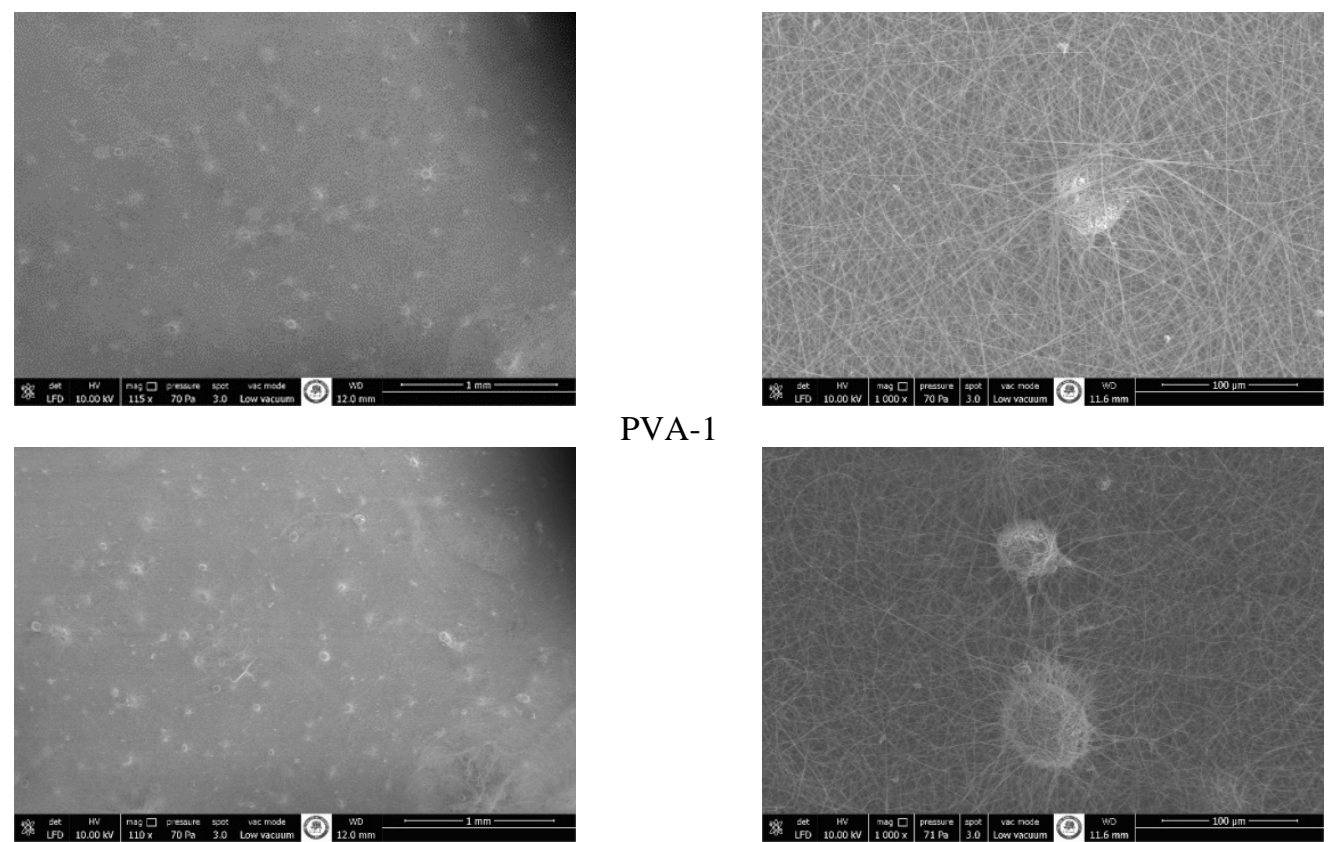

PVA-1

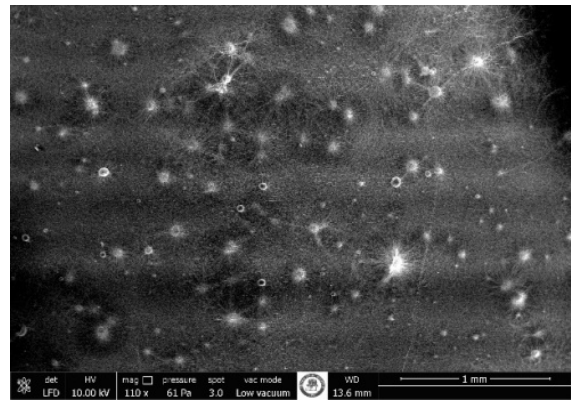

PVA-3
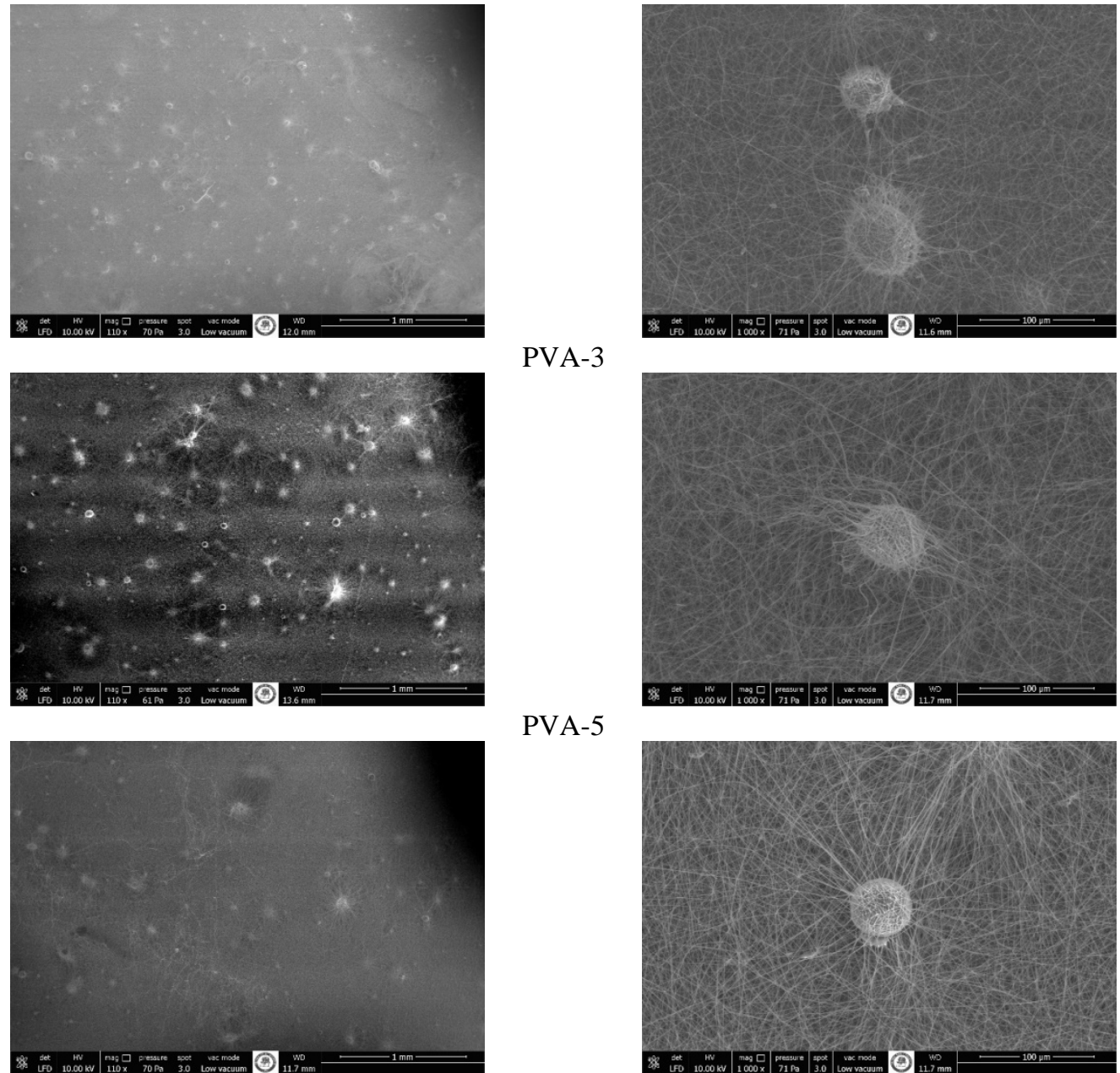

PVA-5

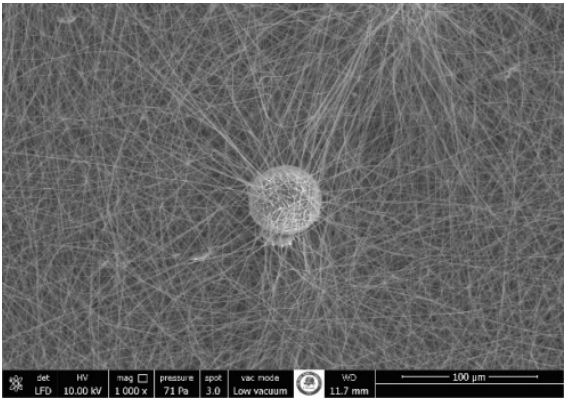

PVA-7
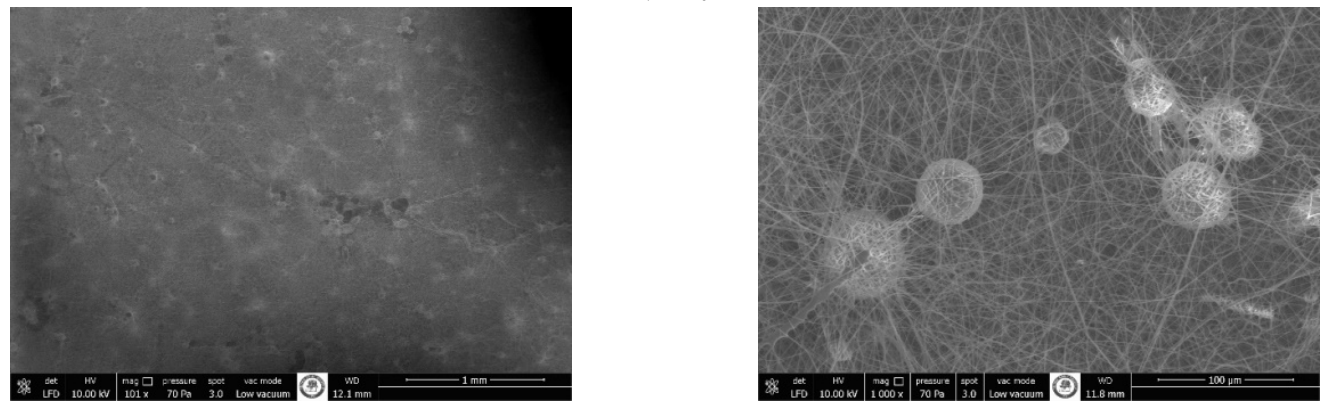

PVA-9

Figure 4. SEM images of PVA nanofibers with various concentrations of microcapsules

As shown in the SEM photos, microcapsules were successfully incorporated into a nanofibrous structure. All of the nanowebs are quite fine, smooth, uniform and without 
beads. Additionally, it is observed that the density of microcapsules in the nanoweb increases as the microcapsule concentration increasement.

In addition to these results, FT-IR spectroscopy confirmed the presence of PVA polymer and St. John's Wort oil loaded microcapsules in the chemical structures of the nanofibers (figure 5).

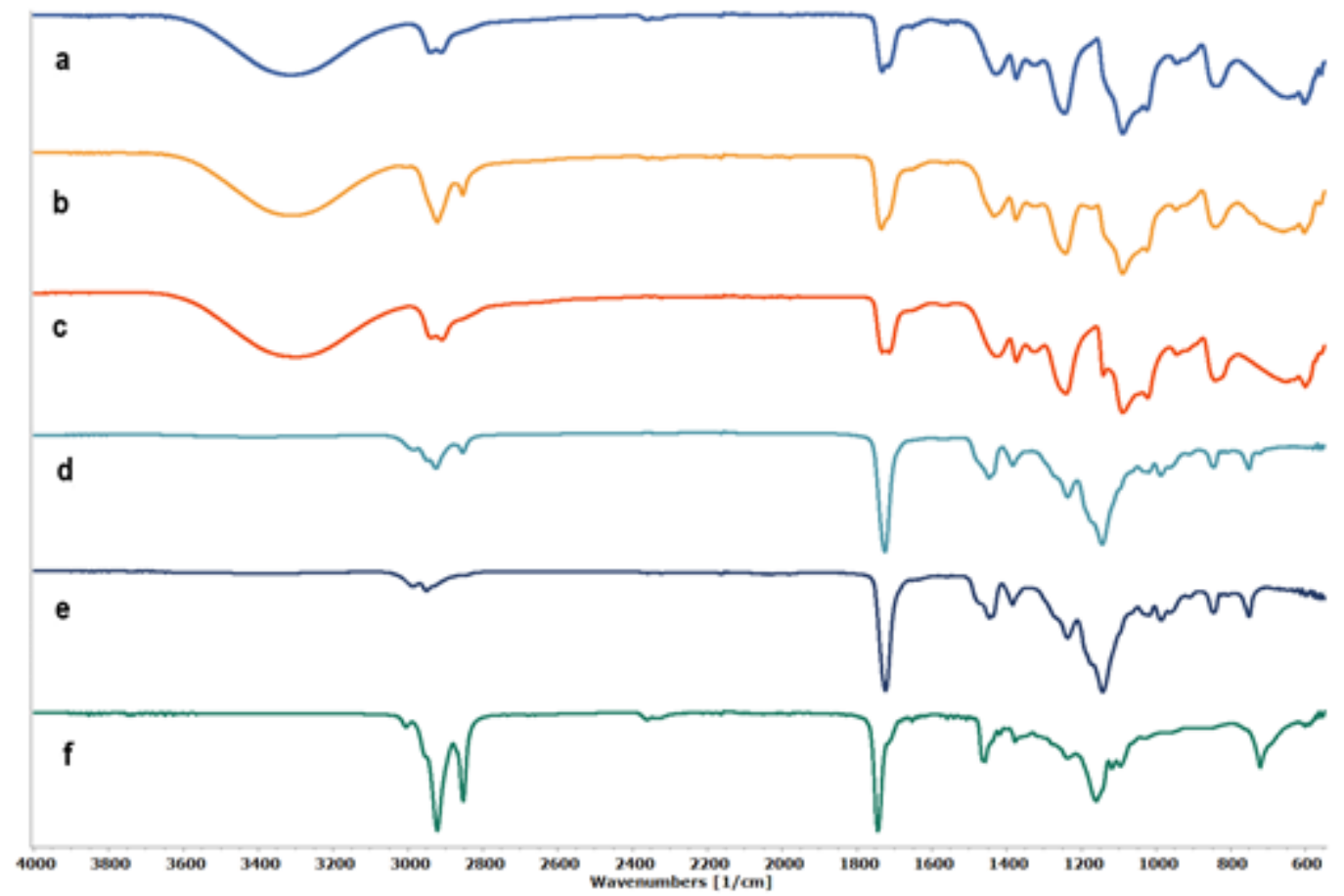

Figure 5. FT-IR spectra of: a - PVA-0 nanofibers; b - PVA-9 nanofibers;

c - PVA polymers; d - St. John's Wort oil loaded PVA/ Eudragit RS 100 microcapsules; e - Eudragit RS 100 polymers; f - St. John's Wort oil

The FT-IR spectrum of PVA demonstrates the primary peaks linked with PVA and PVA nanofibers quite clearly. For instance, the typical strong hydrogen bonded band occurred at approximately 3400-3200 $\mathrm{cm}^{-1}$ wavelength in the spectra of PVA polymer, PVA-0 and PVA-9 nanofibers. Because of the high hydrophilic forces, intramolecular and intermolecular hydrogen bonding is expected to occur among PVA chains. Another important absorption peak was confirmed at $1141 \mathrm{~cm}^{-1}$. This peak arises at $1243 \mathrm{~cm}^{-1}$ and $1245 \mathrm{~cm}^{-1}$ in the spectra of PVA-0 and PVA-9 nanofibers, respectively. The crystallinity of PVA is primarily responsible for this vibrational band, which is related to the carboxyl stretching band (C-O) [9]. The most intense peak in the spectrum of St. John's Wort oil related to C-H stretching peak appearances at $2922 \mathrm{~cm}^{-1}$ and $2853 \mathrm{~cm}^{-1}$. These peaks are seen clearly at $2922 \mathrm{~cm}^{-1}$ and $2853 \mathrm{~cm}^{-1}$ for PVA-9 nanofiber and $2925 \mathrm{~cm}^{-1}$ and $2854 \mathrm{~cm}^{-1}$ for microcapsule spectra [10]. The carbonyl stretching vibration of the ester group is responsible for the stretching bands of Eudragit RS 100 at $1143 \mathrm{~cm}^{-1}$ and $1237 \mathrm{~cm}^{-1}$. These stretching bands are attributed to $1173 \mathrm{~cm}^{-1}$ and $1243 \mathrm{~cm}^{-1}$ for PVA-9 nanofibers and to $1237 \mathrm{~cm}^{-1}$ and $1145 \mathrm{~cm}^{-1}$ for spectra ofmicrocapsules [11].

\section{CONCLUSIONS}

This study achieved the production of St. John's Wort oil loaded microcapsules by the solvent/emulsion evaporation method and electrospinning of PVA nanofibers 
incorporated into the microcapsules successfully. Small, uniform and spherical microcapsules were produced, solution properties of PVA includes different concentrations of microcapsules were determined and also fine, uniform nanofibers incorporated St. John's Wort oil loaded microcapsules were electrospun during the experimental studies. As a result of this study, it is considered that the nanofiber surface containing microcapsules has a high potential for end use as a wound dressing in biomedical applications due to the superior properties of St. John's Wort oil and nanofibers.

\section{REFERENCES}

[1] Bolourchian, N., Bahjat, M., Design and In Vitro Evaluation of Eudragit-Based Extended Release Diltiazem Microspheres for Once-and Twice-Daily Administration: The Effect of Coating on Drug Release Behavior, In: Turk J Pharm Sci, 2019, 16, 3, 340-347, https://doi.org/10.4274/tjps.galenos.2018.24861

[2] Çoban, D.Z., Yener, M., et al., Molecular View to The The Effect of Centaury Oil on Would Healing, In: Cumhuriyet Medical Journal, 2016, 38, 4, 231-239, http://dx.doi.org/10.7197/cmj.v38i2.5000144674

[3] Mukherjee, P.K., Verporte, Rob., et al., Evaluation of In-Vivo Wound Healing Activity of Hypericum Perforatum Leaf Extract on Different Wound Model in Rast, In: Journal of Ethnopharmacology, 2000, 70, 315-321, https://doi.org/10.1016/S0378-8741(99)00172-5

[4] Greeson, M.J., Sanford, B., et al., St. John's Wort (Hypericum Perforatum): a Review of The Current Pharmacology, Toxicological and Clinical Literature, In: Journal of Psychopharmacology, 2001, 153, 402-414, https://doi.org/10.1016/S0378-8741(99)00172-5

[5] Heiskanen, H., Denifl, P., Pitkänen, P., et al., Effect of Concentration and Temperature on The Properties of The Microspheres Prepared Using an Emulsion-Solvent Extraction Process, In: Adv Powder Technol, 2012, 23, 6, 779-786, https://doi.org/10.1016/j.apt.2011.10.007

[6] Hong, Y., Gao, C., Shi, Y., et al., Preparation of Porous Polylactide Microspheres by EmulsionSolvent Evaporation Based on Solution Induced Phase Separation, In: Polym. Adv. Technol., 2005, 16, 8, 622-627, https://doi.org/10.1002/pat.629

[7] Girgin, S., Cengiz Çallığlu, F., Production of Polyvinylpyrrolidone (Pvp)/ St. John's Wort Oil Based Nanofibrous Material, In: National Çukurova Textile Congress (UÇTEK'19), 2019, 337-344

[8] Cengiz, F., Jirsak, O., The effect of salt on the roller electrospinning of polyurethane nanofibers, In: Fibers and Polymers, 2009, 10, 2, 177-184, https://doi.org/10.1007/s12221-009-0177-7

[9] Mansur, H.S., Oréfice, R.L., Mansur, A.A., Characterization of poly (vinyl alcohol)/poly (ethylene glycol) hydrogels and PVA-derived hybrids by small-angle X-ray scattering and FTIR spectroscopy, In: Polymer, 2004, 45, 21, 7193-7202, https://doi.org/10.1016/j.polymer.2004.08.036 [10] Eğri, Ö., Erdemir, N., Production of Hyperivum Perforatum Oil-Loaded Membranes For Wound Dressing Material And in Vitro Tests, Artificial Cells, In: Nanomedicine and Biotechnology An International Journal, 2019, 1404-1415, https://doi.org/10.1080/21691401.2019.1596933

[11] Park, J.M., Park, S.J., Preparation and characterization of water-soluble microcapsule for sustained drug release using Eudragit RS 100, In: Macromolecular Research, 2010, 18, 12, 11911194, https://doi.org/10.1007/s13233-010-1203-8 